\title{
SIMULTANEOUS EVALUATION OF ABACAVIR SULFATE AS WELL AS LAMIVUDINE IN MEDICAL FORMULATIONS BY GRADIENT REVERSED-PHASE HIGH-PERFORMANCE LIQUID CHROMATOGRAPHY TECHNIQUE
}

\author{
ALEKHYA K*, SRINIVASAN MS, SUBRAMANI S, SURYA R, VIJEY AANANDHI M \\ Department of Pharmaceutical Chemistry and Analysis, School of Pharmaceutical Sciences, Vels Institute of Sciences, Technology and \\ Advanced Studies, Pallavaram, Chennai - 603 117, Tamil Nadu, India. Email: alekhya.sps@velsuniv.ac.in
}

Received: 10 October 2018, Revised and Accepted: 11 December 2018

ABSTRACT

Objective: A precise, accurate, simple, and gradient reversed-phase high-performance liquid chromatography (HPLC) method was adapted for the determination of abacavir sulfate (ABV) in combination with lamivudine (LMV) having tablet formulations simultaneously. This method developed has been validated as per the guidelines of ICH.

Method: Waters HPLC has been used in the method with a column named Zorbax $\mathrm{C}_{18}$ with the dimensions as $4.6 \mathrm{~nm} \times 150 \mathrm{~mm}, 3.5 \mu \mathrm{m}$. Phosphate buffer ( $\mathrm{P}^{\mathrm{H}}$ - 3.9) was used as Eluent - A, Eluent - B was methanol, and water and methanol (50:50 v/v) were utilized as diluents. The rate of flow was $1.5 \mathrm{ml} / \mathrm{min}$.

Results: The wavelength of detection has been detected at about $270 \mathrm{~nm}$. Linearity ranges of ABV and LMV were $88-266 \mu \mathrm{g} / \mathrm{ml}$ and $38-116 \mu \mathrm{g} / \mathrm{ml}$, respectively. Retention times of ABV (3.66 min) and LMV (10.71 min) were determined. The values of the study of percentage recovery of ABV and LMV were determined to be within $98.3-99.2 \%$.

Conclusion: The estimation of ABV and LMV in all pharmaceutical dosage forms could be performed successfully by employing this method.

Keywords: Abacavir sulfate, Lamivudine, Reversed-phase high-performance liquid chromatography, Validation, Simultaneous estimation, ICH guidelines, Pharmaceutical dosage forms.

(c) 2018 The Authors. Published by Innovare Academic Sciences Pvt Ltd. This is an open access article under the CC BY license (http://creativecommons. org/licenses/by/4. 0/) DOI: http://dx.doi.org/10.22159/ajpcr.2018.v11s4.31708

\section{INTRODUCTION}

Chemically, abacavir sulfate (ABV) is (1S-cis)-4-[2-amino-6(cyclopropylamino)-9H-purin-9-yl]cyclopent-2-en-1-yl\}methanol sulfate [8-11]. It acts as a nucleoside reverse transcriptase inhibitor. It is converted into a metabolite which is active called as carbovir triphosphate (CBV-TP) equivalent to deoxyguanosine - 5 ' - triphosphate (dGTP). CBV-TP acts by hindering the reverse transcriptase activity of HIV-1. It competes with a natural substrate called dGTP which leads to DNA growth termination.

Chemically, lamivudine (LMV) is 4-amino-1-[(2R,5S)-2-(hydroxymethyl)1,3-oxathiolan-5-yl]pyrimidin-2-one [8-10]. LMV is an antiretroviral drug which acts by getting incorporated within viral DNA. HIV reverse transcriptase enzyme is inhibited competitively by LMV. This drug serves as a chain terminator for the synthesis of DNA.

Literature survey explains that several ultraviolet (UV) spectroscopy [1,2], reversed-phase high-performance liquid chromatography (RP-HPLC) [3-6] and high-performance thin-layer chromatography [7] methods are available for the estimation of ABR and LMV. The purpose of the current research is to establish an innovative method which gives advanced analytical techniques for identification, detection, resolution, accuracy, and precision.

\section{METHODS}

\section{Instrumentation}

HPLC (make-waters) was used for this method. It has a quaternary pump. The column used here was the column named Zorbax luna $\mathrm{C}_{18}$ with the dimensions as $4.6 \mathrm{~mm} \times 150 \mathrm{~mm}, 3.5 \mu \mathrm{m}$. The drugs were discovered using UV Detector (Empower - 2 Software). The weighing balance used here was Sartorius make. Sonicator (spectra lab) and $\mathrm{pH}$ meter (polmon) were also used during the method development and validation of these drugs.

Reagents and chemicals

HPLC grade Methanol, Milli - Q grade water, analytical reagent grade ammonium dihydrogen phosphate, Analytical Reagent Grade diammonium hydrogen phosphate, and Analytical Reagent Grade trifluoroacetic acid were used. Pure samples of ABR and LMV were procured from Hetero labs limited, Hyderabad.

\section{Chromatographic conditions}

The analysis was performed using waters HPLC. The method involves a column named Zorbax $\mathrm{C}_{18}$ with the dimensions as $4.6 \mathrm{~mm} \times 150 \mathrm{~mm}$, $3.5 \mu \mathrm{m}$ being used as a stationary phase. The resolution for the drugs ABR and LMV was achieved using the mobile phase, phosphate buffer $(\mathrm{pH}-3.9)$ and methanol and water in 50:50 combination in gradient mode. The rate of flow of the eluent was $1.5 \mathrm{ml} / \mathrm{min}$. The runtime was $20 \mathrm{~min} .10 \mu \mathrm{l}$ was the injection volume and $270 \mathrm{~nm}$ was the detection wavelength reported. The gradient chromatography conditions were as shown in Table 1.

\section{Solution preparation}

Phosphate buffer ( $\mathrm{pH}$ - 3.9)

Ammonium dihydrogen phosphate $(2.3 \mathrm{~g})$ and diammonium hydrogen phosphate $(1.32 \mathrm{~g})$ were dissolved in $1 \mathrm{~L}$ of distilled water. The $\mathrm{pH}$ was maintained at $3.9 \pm 0.05$ using $50 \% \mathrm{~V} / \mathrm{V}$ trifluoro acetic acid $(10 \mathrm{ml}$ of TFA was transferred into a volumetric flask of $200 \mathrm{ml}$ capacity). The volume of the flask was made up to the mark using distilled water. The above solution was passed through a filter named membrane having dimensions $0.22 \mu \mathrm{m}$. 


\section{Preparation of the diluent}

Methanol and water were degassed and mixed in the ratio of 50:50. This solution was called the diluent.

\section{Preparation of the Standard Solution}

The drugs ABV ( $88 \mathrm{mg}$ ) and LMV ( $38 \mathrm{mg}$ ) were transferred into a $50 \mathrm{ml}$ standard flask. The flask was sonicated after adding $30 \mathrm{ml}$ of the diluent until the drugs dissolve. The volume was made up to the mark with the diluent.

\section{Calibration curves}

Linearity for the drugs was observed as $100-300$ ppm for ABV and 40-120 ppm for LMV. The values were in a linear range. The linearity plot for $\mathrm{ABV}$ and $\mathrm{LMV}$ was plotted as response factor versus concentration (Figs. 1 and 2 and Tables 2 and 3 ).

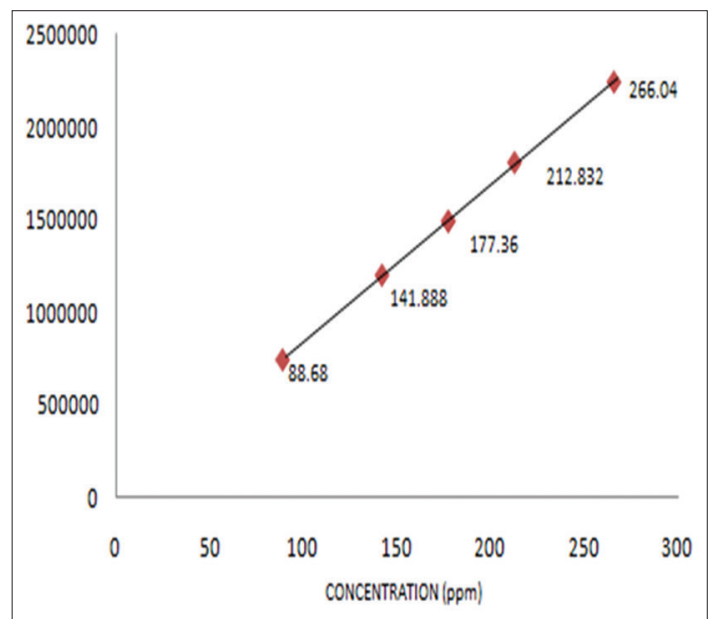

Fig. 1: Linearity curve of abacavir sulfate

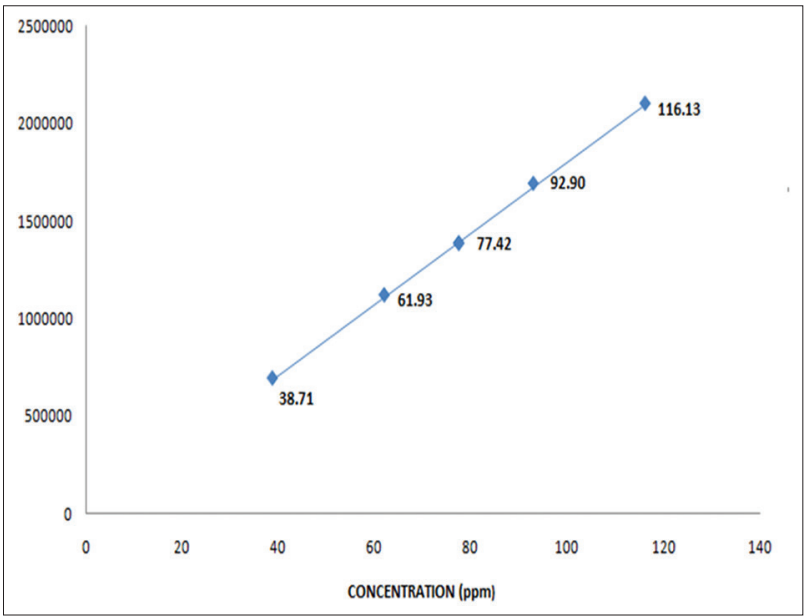

Fig. 2: Linearity curve of lamivudine

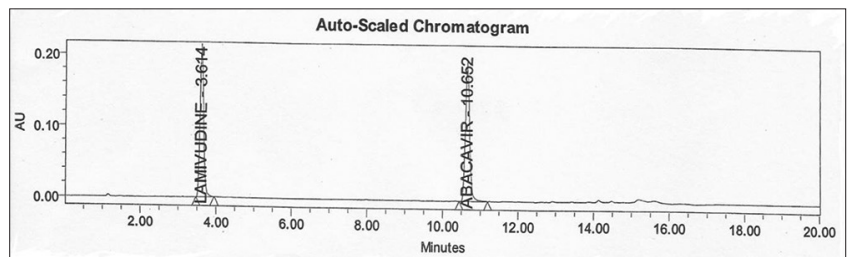

Fig. 3: Typical chromatogram of abacavir sulfate and lamivudine

\section{Analysis of tablet formulation}

A total of 20 tablets were collected, powdered, and weighed. LMV (300 mg) was added to a $100 \mathrm{ml}$ standard flask, $60 \mathrm{ml}$ of diluent was then added and kept in a water bath for $30 \mathrm{~min}$ at a temperature of $20-25^{\circ} \mathrm{C}$. The flask was diluted with the diluent until it reaches the mark. The solution of the sample was centrifuged for $5 \mathrm{~min}$ at a speed of $5000 \mathrm{rpm} .5 \mathrm{ml}$ of the above solution was added to $200 \mathrm{ml}$ of the standard flask and diluted until it reaches the mark using the diluent. This was passed through a filter called membrane with $0.45 \mu \mathrm{m}$ dimension. Initially, some ml was discarded.

\section{Procedure}

The column was equilibrated for half an hour at $1.5 \mathrm{ml} / \mathrm{min}$ flow rate. $10 \mu \mathrm{l}$ of the blank solution (diluent) was injected into the system first, followed by standard solution (5 injections) and then the sample solution. The chromatograms were recorded and the peak responses were computed. The typical chromatogram is shown in Fig. 3.

\section{Validation of HPLC method \\ Specificity}

The chromatograms of the mixed standard and sample solutions were compared. The specificity of the RP-HPLC method was determined. The retention time, tailing factor, and resolution were also evaluated. The correlation coefficient was found to be good, and the results were shown in Table 1a.

\section{Linearity}

A graph was plot between concentration and response for the drugs to establish linearity of detector response. At about $50-150 \%$ of test concentration, the detector responses were linear. The correlation coefficient was within the acceptable level. The reports were as reported in Tables 2 and 3. The linearity plot was obtained as shown in Figs. 1 and 2.

Table 1: Gradient program of the optimized process

\begin{tabular}{llll}
\hline Time (min) & Rate of flow & Eluent A \% & Eluent B \% \\
\hline $0 \mathrm{~min}$ & $1.5 \mathrm{ml} / \mathrm{min}$ & 95 & 5 \\
$10 \mathrm{~min}$ & $1.5 \mathrm{ml} / \mathrm{min}$ & 65 & 35 \\
$14 \mathrm{~min}$ & $1.5 \mathrm{ml} / \mathrm{min}$ & 20 & 80 \\
$15 \mathrm{~min}$ & $1.5 \mathrm{ml} / \mathrm{min}$ & 95 & 5 \\
$20 \mathrm{~min}$ & $1.5 \mathrm{ml} / \mathrm{min}$ & 95 & 5 \\
\hline
\end{tabular}

Table 1a: System suitability

\begin{tabular}{llll}
\hline Parameter & ABV & LMV & Acceptance criteria \\
\hline Tailing factor & 1.16 & 1.16 & NMT 2 \\
Resolution (RS) & 6.5 & & $>2$ \\
Plate number (N) & 41549 & 6089 & $>2000$ \\
Capacity factor & 4.54 & & K $>2$ \\
Peak summery factor & 1.006 & 0.956 & $0.9-1.1$ \\
\hline
\end{tabular}

ABV: Abacavir sulfate, LMV: Lamivudine

Table 2: Linearity of detection response for ABV

\begin{tabular}{llll}
\hline Levels & Concentration (ppm) & Mean area & \%RSD \\
\hline Level 1 & 88.68 & 748,537 & 0.24 \\
Level 2 & 141.888 & $1,203,886$ & \\
Level 3 & 177.36 & $1,494,144$ & \\
Level 4 & 177.36 & $1,494,144$ & \\
Level 5 & 212.832 & $1,810,109$ & \\
Level 6 & 266.04 & $2,243,040$ & 0.71 \\
& & Slope & 8442.76 \\
& & Y-intercept & 1569.6 \\
& & \% 0F Y-intercept & 0.11 \\
& & Correlation coefficient & 0.99991 \\
\hline
\end{tabular}

ABV: Abacavir sulfate, RSD: Relative standard deviation 
Precision

The value of the precision for the proposed method was $0.43 \%$ relative standard deviation (RSD) ABV and $0.64 \%$ RSD LMV. This indicates good precision value for the sample being analyzed which is shown in Tables 4 and 5.

Accuracy

Recovery studies were used to determine how accurate the developed method is at different measures of the test solution usually three which were analyzed previously. The standard solution was added to the

Table 3: Linearity of detection response for LMV

\begin{tabular}{|c|c|c|c|}
\hline Levels & Concentration (ppm) & Mean area & $\%$ RSD \\
\hline Level 1 & 38.71 & 696,053 & 0.59 \\
\hline Level 2 & 61.936 & $1,123,050$ & \\
\hline Level 3 & 77.42 & $1,389,538$ & \\
\hline Level 4 & 77.42 & $1,389,538$ & \\
\hline Level 5 & 92.904 & $1,695,335$ & \\
\hline \multirow[t]{5}{*}{ Level 6} & 116.13 & $2,106,171$ & 0.97 \\
\hline & & Slope & 18250.56 \\
\hline & & Y-intercept & -1301.12 \\
\hline & & $\%$ 0F Y-intercept & -0.94 \\
\hline & & Correlation coefficient & 0.99982 \\
\hline
\end{tabular}

LMV: Lamivudine, RSD: Relative standard deviation

Table 4: Method precision for ABV

\begin{tabular}{lll}
\hline Sample no. & Peak area & \% Assay \\
\hline 1 & $1,537,605$ & 102.5 \\
2 & $1,530,101$ & 102 \\
3 & $1,533,166$ & 102.2 \\
4 & $1,542,077$ & 102.9 \\
5 & $1,522,358$ & 101.5 \\
6 & $1,533,156$ & 102.2 \\
& Mean & 102.2 \\
& SD & 0.47 \\
& \% RSD & 0.46 \\
\hline
\end{tabular}

ABV: Abacavir sulfate, RSD: Relative standard deviation

Table 5: Method precision for LMV

\begin{tabular}{lll}
\hline Sample no. & Peak area & \% Assay \\
\hline 1 & $1,347,989$ & 100 \\
2 & $1,336,374$ & 99.1 \\
3 & $1,339,601$ & 99.3 \\
4 & $1,353,322$ & 100.4 \\
5 & $1,334,982$ & 99 \\
6 & $1,354,089$ & 100.4 \\
& Mean & 99.7 \\
& SD & 0.64 \\
& \% RSD & 0.64 \\
\hline
\end{tabular}

LMV: Lamivudine, RSD: Relative standard deviation solution containing the drugs (ABR and LMV) within the concentration range. The quantity of the recovered drug at each level $(n=6)$ was determined, and its percentage recovery was also estimated. The recovery studies of ABR and LMV were evaluated to be 98.73 and 99.06, respectively. The values are given in Tables 5 and 6. The recovery studies prove that the current method had no interference with the other things which were there in the formulation. The reports were shown in Tables 6 and 7.

\section{Robustness}

By changing the temperature, flow rate and $\mathrm{p}^{\mathrm{H}}$ of the given method robustness were determined. The method was found to be robust and the results was represented in Tables 8 and 9.

\section{System suitability parameters}

The system suitability parameters of this method were calculated. The values of percentage RSD were found to be within the limits for 5 replicate injections of $\mathrm{ABV}$ and $\mathrm{LMV}$ and were found to be 0.48 and 0.65 . The tailing factors for the drug peaks ABV and LMV were 1.16 and 1.16, respectively. The number of theoretical plates for abacavir and LMV was 41,549 and 68,109 which was found to be within limits. The system suitability parameters were calculated. The values were found to be within limits and are represented in Table 1.

\section{RESULTS AND DISCUSSION}

The current method employs a RP-HPLC procedure using a column named Zorbax luna $\mathrm{C}_{18}$ with dimensions $4.6 \mathrm{~mm} \times 150 \mathrm{~mm}$ and $3.5 \mu$. The eluent used here was phosphate buffer $(\mathrm{pH}-3.9)$ and methanol and water (50:50). To select the wavelength for sampling, the drugs were measured using UV-visible spectrophotometer in 200-400 nm wavelength range. After scanning the spectrum of each one of the drugs, $270 \mathrm{~nm}$ was finally selected as a wavelength suitable for the estimation of the drugs of our interest. The resolution for ABR and LMV was achieved in $20 \mathrm{~min}$ (runtime) with a given flow rate $(1.5 \mathrm{ml} / \mathrm{min}$ ) and was found to the best.

The linearity values for ABV and LMV were found to be within the range (100-300 ppm and 40-120 ppm, respectively). The method of interest was evaluated for accuracy by addition of a standard drug solution containing the drugs within the concentration range of $\mathrm{ABV}$ and for LMV, and it was added to the previously analyzed test solution. The recovery studies for ABV and LMV were $98.73 \%$ and $99.06 \%$, respectively. The method of interest was evaluated for precision and the percentage RSD values were reported as 0.43 for ABV and 0.64 for LMV. This indicates that a good precision value for the sample was reported. By changing the temperature, flow rate or $\mathrm{pH}$ of the given method, the suitability parameters of the system were observed to be within limits. Hence, the method is said to be robust. The validation parameters such as selectivity and sensitivity of our method of interest were proved to be acceptable because the parameters such as tailing factor, the number of theoretical plates, separation factor, resolution, and statistical parameters and results of the analysis were found be within limits.

Table 6: Accuracy data for ABV

\begin{tabular}{|c|c|c|c|c|c|c|c|}
\hline $\begin{array}{l}\text { Concentration of spiked } \\
\text { level(\%) }\end{array}$ & Sample no & Amount added & Amount found & \% Recovery & Mean & SD & $\%$ RSD \\
\hline \multirow[t]{3}{*}{50} & 1 & 84.8 & 83.25 & 98.2 & 98.9 & 1.04 & 1.05 \\
\hline & 2 & 85.03 & 85.08 & 100.1 & & & \\
\hline & 3 & 84.86 & 83.47 & 98.4 & & & \\
\hline \multirow[t]{3}{*}{100} & 1 & 172.83 & 171.37 & 99.2 & 99.0 & 0.62 & 0.63 \\
\hline & 2 & 172.8 & 171.88 & 99.5 & & & \\
\hline & 3 & 173.14 & 170.17 & 98.3 & & & \\
\hline \multirow[t]{3}{*}{150} & 1 & 255.15 & 255.15 & 98.1 & 98.3 & 0.40 & 0.41 \\
\hline & 2 & 259.71 & 256.69 & 98.8 & & & \\
\hline & 3 & 259 & 254.15 & 98.1 & & & \\
\hline
\end{tabular}

ABV: Abacavir sulfate, RSD: Relative standard deviation, SD: Standard deviation 
Table 7: Accuracy data for LMV

\begin{tabular}{|c|c|c|c|c|c|c|c|}
\hline $\begin{array}{l}\text { Concentration of spiked } \\
\text { level }(\%)\end{array}$ & sample no & $\begin{array}{l}\text { Amount of the drug } \\
\text { added (mg) }\end{array}$ & $\begin{array}{l}\text { Amount of the drug } \\
\text { found (mg) }\end{array}$ & $\begin{array}{l}\text { Percentage } \\
\text { recovery }\end{array}$ & $\begin{array}{l}\text { Mean } \\
\text { value }\end{array}$ & SD & \% RSD \\
\hline \multirow[t]{3}{*}{50} & 1 & 38.2 & 37.45 & 98.0 & 99.2 & 1.11 & 1.12 \\
\hline & 2 & 38.06 & 38.13 & 100.2 & & & \\
\hline & 3 & 38.18 & 37.97 & 99.4 & & & \\
\hline \multirow[t]{3}{*}{100} & 1 & 75.97 & 75.64 & 99.6 & 99.2 & 0.55 & 0.55 \\
\hline & 2 & 76.19 & 75.79 & 99.5 & & & \\
\hline & 3 & 75.96 & 74.92 & 98.6 & & & \\
\hline \multirow{2}{*}{150} & 2 & 113.36 & 112.44 & 99.2 & & & \\
\hline & 3 & 113.71 & 111.9 & 98.4 & & & \\
\hline
\end{tabular}

LMV: Lamivudine, RSD: Relative standard deviation, SD: Standard deviation

Table 8: ABV robustness

\begin{tabular}{llll}
\hline Parameters & Results & RT (min) & Mean peak area (n=5) of abacavir \\
\hline Flow rate & $1.5 \mathrm{ml} / \mathrm{min}$ & 10.701 & $1,543,762$ \\
Flow rate & $1.4 \mathrm{ml} / \mathrm{min}$ & 12.359 & $1,623,612$ \\
Flow rate & $1.6 \mathrm{ml} / \mathrm{min}$ & 9.281 & $1,183,133$ \\
Column temperature & $45^{\circ} \mathrm{C}$ & 10.452 & $1,482,427$ \\
Column temperature & $55^{\circ} \mathrm{C}$ & 10.679 & $1,468,953$ \\
Buffer Ph & 3.7 & 11.249 & $1,543,198$ \\
Buffer pH & 4.2 & 10.129 & $1,574,944$ \\
\hline
\end{tabular}

ABV: Abacavir sulfate, RT: Retention time, RSD: Relative standard deviation, SD: Standard deviation

Table 9: Results of robustness (LMV)

\begin{tabular}{llll}
\hline Parameters & Results & RT (min) & Mean peak area (n=5) of LMV \\
\hline Flow rate & $\left(1.5 \mathrm{ml} / \mathrm{min}, 50^{\circ} \mathrm{C}\right)$ & 3.675 & $1,352,313$ \\
Flow rate & $1.4 \mathrm{ml} / \mathrm{min}$ & 4.592 & $1,554,365$ \\
Flow rate & $1.6 \mathrm{ml} / \mathrm{min}$ & 2.973 & $1,096,323$ \\
Column temperature & $45^{\circ} \mathrm{C}$ & 3.842 & $1,474,128$ \\
Column temperature & $55^{\circ} \mathrm{C}$ & 3.290 & 0.42 \\
Buffer pH & 3.7 & 4.702 & 0.12 \\
Buffer pH & 4.2 & 3.482 & 0.04 \\
\hline
\end{tabular}

LMV: Lamivudine, RT: Retention time, RSD: Relative standard deviation, SD: Standard deviation

\section{CONCLUSION}

The current work explains a simple, robust, economical, and noninterfering simultaneous method for the evaluation of ABV and LMV using RP-HPLC technique. The present procedure was observed as a simple, accurate, economic, reproducible, and precise while performing the analysis of drug formulations having both the drugs.

\section{ACKNOWLEDGMENT}

I express my heartfelt gratitude to Vels Institute of Sciences, Technology and Advanced Studies, for providing me the research and library facilities for my research work. I also express my sincere thanks to Aurobindo Pharmaceuticals, Hyderabad, for providing me the drugs.

\section{REFERENCES}

1. Sudha T, Saminathan J, Anusha K, Keerthi M, Bhargavi Y, Ganesan.V. Simultaneous UV spectrophotometric estimation of lamivudine And abacavir sulphate in bulk and in tablet dosage form. J Chem Pharm Res 2010;2:45-51.

2. Nagulwar PV, Kishor BP. Simultaneous estimation of abacavir, lamivudine and zidovudine in combined tablet dosage form by UV spectrophotometric method. J Chem Pharm Res 2011;2:610-14.

3. Kumar BR, Priyanka M, Priyamvada BN, Prasad K, Mallikarjuna K, Anuradha B. Method development and validation for the determination of abacavir and lamivudine by using RP-HPLC in pure and pharmaceutical dosage form. Int J Pharm World Res 2012;3:2-3

4. Sudha T, Kumar VR, Hemalatha PV. RP-HPLC method for the simultaneous estimation of lamivudine and abacavir sulphate in tablet dosage form. Int J Pharm Biol Res 2010;1:108-13

5. Nagulwar PV, Kishor BP. Development of RP-HPLC method for the simultaneous estimation of abacavir and lamivudine in combined tablet dosage form. Int J Pharm Appl 2012;3:293-6.

6. Mohideen S, Kumar GV, Surendranath Y, Kumar PS, Krishnan SN. Validated RP-HPLC for simultaneous estimation of abacavir and lamivudine in tablet dosage form. Int J Pharm Pharm Sci 2012;4:349-56.

7. Sudha T, Raviumar VR, Hemalatha PV. Validated HPTLC method for simultaneous determination of lamivudine and abacavir sulphate in tablet dosage form. Int J Pharm Sci Res 2012;1:107-11.

8. Kumar AP, Parthasarathi G, Sudheer AP, Mothi SN, Swamy VH, Rao S. Incidence and risk factors of renal impairment in HIV-1 infected patients receiving tenofovir based antiretroviral therapy in a South Indian hospital. Int J Pharm Pharm Sci 2017:9:152-5.

9. Wolf E, Blankenburg M, Bogner JR, Becker W, Gorriahn D, Mueller MC, et al. Cost impact of prospective HLA-B*5701-screening prior to abacavir/lamivudine fixed dose combination use in Germany. Eur J Med Res 2010;15:145-51.

10. Kauf TL, Farkouh RA, Earnshaw SR, Watson ME, Maroudas P, Chambers MG, et al. Economic efficiency of genetic screening to inform the use of abacavir sulfate in the treatment of HIV. Pharmacoeconomics 2010;28:1025-39.

11. Kubaeva MB, Sh SH, Loskutova EE. Cost-effectiveness of Hla-B*5701 prospective genetic screening of hypersensitivity to abacavir. Asian J Pharm Clin Res 2018;11:281-3. 